
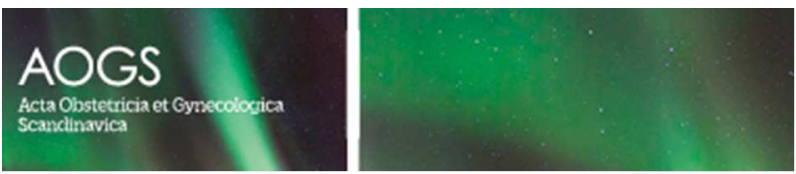

\title{
Towards national comprehensive gestational diabetes screening -Consequences for neonatal outcome and care
}

\begin{tabular}{|c|c|}
\hline Journal: & Acta Obstetricia et Gynecologica Scandinavica \\
\hline Manuscript ID & AOGS-16-0245.R2 \\
\hline Wiley - Manuscript type: & Original Research Article \\
\hline Date Submitted by the Author: & $\mathrm{n} / \mathrm{a}$ \\
\hline Complete List of Authors: & $\begin{array}{l}\text { Koivunen, Sanna; Oulu University Hospital, Obstetrics and Gynaecology; } \\
\text { PEDEGO Research Unit, Obstetrics and gynecology; National Institute of } \\
\text { Health and Welfare, Child and Adolescent Health and Wellbeing Unit } \\
\text { Asikainen, Annukka; Oulu University Hospital, Obstetrics and Gynaecology; } \\
\text { PEDEGO Research Unit, Obstetrics and gynecology; National Institute of } \\
\text { Health and Welfare, Child and Adolescent Health and Wellbeing Unit } \\
\text { Bloigu, Aini; National Institute of Health and Welfare, Child and Adolescent } \\
\text { Health and Wellbeing Unit } \\
\text { Gissler, Mika; National Institute of Health and Welfare, Information } \\
\text { Department } \\
\text { Pouta, Anneli; National Institute for Health and Welfare, Child and } \\
\text { Adolescent Health and Wellbeing Unit } \\
\text { Kajantie, Eero; National Institute of Health and Welfare, Chronic Disease } \\
\text { Prevention Unit; Oulu University Hospital, Obstetrics and Gynaecology; } \\
\text { Helsinki University Central Hospital, Children's Hospital } \\
\text { Vääräsmäki, Marja; Oulu University Hospital, Obstetrics and Gynaecology; } \\
\text { PEDEGO Research Unit, Obstetrics and gynecology; National Institute of } \\
\text { Health and Welfare, Child and Adolescent Health and Wellbeing Unit }\end{array}$ \\
\hline Keywords: & Gestational diabetes mellitus \\
\hline
\end{tabular}

\section{SCHOLARONE ${ }^{\text {Wx }}$}

Manuscripts 
1

2

3

4

5

6

$\begin{array}{ll}7 & 1\end{array}$

82 9

103

114
Towards national comprehensive gestational diabetes screening -

Consequences for neonatal outcome and care

Short title: Neonatal care after comprehensive GDM screening

Sanna Koivunen, ${ }^{1,2,{ }^{*}}$ Annukka Torkki, ${ }^{1,2, *}$ Aini Bloigu, ${ }^{2}$ Mika Gissler, ${ }^{5}$ Anneli Pouta, ${ }^{2}$ Eero

Kajantie, ${ }^{1,3,4}$ and Marja Vääräsmäki ${ }^{1,2}$

*Equal contribution

${ }^{1}$ Department of Obstetrics and Gynecology and Medical Research Center Oulu, Oulu University

Hospital and University of Oulu, Finland

${ }^{2}$ Child and Adolescent Health and Wellbeing Unit, National Institute for Health and Welfare, Oulu,

Finland

${ }^{3}$ Chronic Disease Prevention Unit, National Institute for Health and Welfare, Helsinki, Finland

${ }^{4}$ Children's Hospital, Helsinki University Central Hospital and University of Helsinki, Helsinki,

Finland,

${ }^{5}$ Information Department, National Institute for Health and Welfare, Helsinki, Finland

\section{Correspondence to Sanna Koivunen}

Corresponding author: Sanna Koivunen, sanna.koivunen@oulu.fi.

Address: Sanna Koivunen

P.O. Box 23

90029 OYS, Finland

Tel. +35883153746

Fax. +35883154499

Word count: 3089 (excluding tables, title page and references)

Tables: Three tables and two supplementary tables

One supplementary figure. 
732 Conflicts of interest notification: None to declare.

$\begin{array}{ll}8 & 33\end{array}$

1034 Details of ethical approval: The study was approved by the regional Ethics Committee in the 113 12 $13^{36}$

1437

15

$16^{38}$

17

18

19

20

21

22

23

24

25

26

27

28

29

30

31

32

33

34

35

36

37

38

39

40

41

42

43

44

45

46

47

48

49

50

51

52

53

54

55

56

57

58

59

60

orthern Ostrobothnia Hospital District, Number 2008/43, date of approval

2008-6-19. 
Abstract

Introduction: The change from risk-factor based to nearly comprehensive| screening of gestational diabetes (GDM) identifies more but milder cases of the disease. The main aim of this study was to evaluate the effect of this screening policy change on neonatal outcomes and care.

Material and methods: A population-based register study in Finland. GDM cases during risk factorbased (year 2006, n=5179) and comprehensive (2010, n=6679) screenings were identified through Medical Birth Register. All singletons without maternal GDM or pre-pregnancy diabetes served as controls ( $\mathrm{n}=51746$ and 52 386, respectively). The main outcomes were macrosomia, neonatal hypoglycemia and the need of care in a neonatal ward.

Results: In the GDM group, the mean birth weight decreased between the study years from $3660 \mathrm{~g}$ to $3595 \mathrm{~g}$ and the prevalence of macrosomia from $5.6 \%$ to $4.1 \%$ even after adjustment for maternal age, parity and pre-pregnancy body mass index (BMI). The adjusted mean difference in birth weight between GDM and control newborns decreased from $70 \mathrm{~g}$ to $22 \mathrm{~g}$ between the study years. The prevalence of neonatal hypoglycemia increased from $18.0 \%$ to $22.1 \%$ in the GDM group. However, neonatal hypoglycemia was more often treated without care in a neonatal ward. The proportion of infants treated at a neonatal ward decreased in both the GDM and control groups between the study years.

Conclusions: In newborns, comprehensive GDM screening led to decreased mean birth weight and macrosomia rates, but the prevalence of neonatal hypoglycemia increased. This places substantial demands for delivery hospitals and healthcare resources.

Keywords: Gestational diabetes mellitus, diagnosis, screening, neonatal outcome, neonatal care
Comment [VS1]: Since not all women were screened, you might want to use: "nearly comprehensive" or "broad". The same applies for the title.

Comment [EK2]: Please see also our response to comment 1 of Reviewer 1 .

Comment [SK3]: The aim was change the screening method as comprehensive. This and our previous studies tells how this implementation went. 
764 Abbreviations

865

966

BMI Body mass index

CI Confidence interval

GDM Gestational diabetes mellitus

GW Gestational weeks

HAPO Hyperglycemia and Adverse Pregnancy Outcome study

IADPSG International Association of the Diabetes and Pregnancy Study Group

ICD 10 International Statistical Classification of Diseases and Related Health Problems

LGA Large for gestational age

MBR Finnish medical Birth Register

OGTT Oral glucose tolerance test

OR Odds ratio

SD Standard deviation

Key message: Comprehensive screening of GDM led to decreased mean birth weight and macrosomia rates, but the prevalence of neonatal hypoglycemia increased. 


\section{$\begin{array}{lll}7 & 81 & \text { Introduction }\end{array}$}

8

Gestational diabetes mellitus (GDM), defined as an abnormal glucose metabolism with onset or first recognition during pregnancy, is associated with an increased risk of perinatal complications and neonatal morbidities such as hypoxia, hypoglycemia, hyperbilirubinemia and birth trauma due to macrosomia (1-6). In the long term, prenatal exposure to maternal GDM increases the risk of overweight and metabolic syndrome in the offspring during childhood and adolescence (7-13).

GDM is common. Using the uniform diagnostic criteria of the International Association of the Diabetes and Pregnancy Study Group (IADPSG) based on the Hyperglycemia and Adverse Pregnancy Outcome (HAPO) study, its prevalence varies from 9.3 to $25.5 \%$ in different populations (14). The reason for this large variation in frequency is unclear, but it may partly depend on genetic susceptibility and obesity. It is important to diagnose GDM because its effective treatment reduces perinatal complications and may also improve the offspring's long-term outcomes (7, 15-18).

In Finland, new national screening and diagnostic guidelines for GDM were launched in 2008. The previously used risk factor-based screening was replaced with nearly comprehensive screening, excluding only the estimated approximately $20 \%$ of women at very low risk of GDM. The shift to wide-scale screening led to a significant increase in women with mainly diet-treated GDM, who were more often primiparous and had a lower body mass index (BMI) (19). Our aim was to evaluate how this change of policy affected the perinatal outcome and the need for care at a neonatal ward. 


\section{Material and methods}

Medical Birth Register reformed in 2004 to improve its reliability. The MBR contains data on all mothers with live births or stillbirths with a gestational age $\geq 22$ weeks or a birth weight $\geq 500 \mathrm{~g}$. For each delivery in Finland, a structured form for the MBR is completed by the delivery hospital within 7 days of delivery, including data regarding the course and complications of the pregnancy and the delivery, as well as information related to the perinatal health of the newborn, such as birth weight and length, Apgar score, cord blood $\mathrm{pH}$, treatments and diagnosis with ICD-10 codes until the 7th day after birth. The register is completed using data compiled by the Population Register Centre on live births and by Statistics Finland regarding stillbirths and infant deaths. The data quality of the MBR has been shown to be high for most of the applicable variables $(20,21)$.

\section{Definition of GDM}

Since 2004, the MBR has also included information on whether the oral glucose tolerance test (OGTT) was performed to diagnose GDM, whether the result was abnormal and whether insulin treatment was initiated. For the present study, mothers were identified through the MBR using these OGTT data.

A diagnosis of GDM was applied if a woman had an abnormal OGTT result or insulin therapy was initiated during pregnancy according to the MBR. After the exclusion of multiple births, mothers with pre-pregnancy type 1 or type 2 diabetes (ICD-10 codes O24.0 or O24.1) and preterm delivery $(<37$ gestational weeks $[\mathrm{gw}])$ of neonates with abnormally high birth weight standard deviation (>3SD) scores (birth weight standardised for the length of gestation), which are likely to reflect erroneous recordings, 5179 (9.1\%) women in 2006 and 6679 (11.3\%) women in 2010 fulfilled the GDM criteria. Women who did not fulfil the GDM criteria served as controls, numbering 51,746 for 2006 and 52,386 for 2010 (Figure S1).

\section{Screening for GDM}

In 2008, new national guidelines to screen and diagnose GDM were launched in Finland. Risk factor-based screening was replaced by nearly comprehensive screening (Table I). According to both screening policies, both the screening and diagnosis of GDM were carried out via a standard 2 h $75 \mathrm{~g}$ OGTT, which was mainly performed between the $24^{\text {th }}$ and $28^{\text {th }} \mathrm{gw}$. For both years, the OGTT was recommended between the $12^{\text {th }}$ and $16^{\text {th }} \mathrm{gw}$ for high-risk groups (before 2008, prior 
GDM; from 2008 onwards, prior GDM, BMI 35 or more or polycystic ovary syndrome with insulin resistance), and if the result was normal, the OGTT would be repeated between the $24^{\text {th }}$ and $28^{\text {th }} \mathrm{gw}$. In the OGTT, blood glucose concentrations are measured after an overnight fast. Venous plasma glucose equal to or higher than $5.3,10.0$, and $8.6 \mathrm{mmol} / \mathrm{l}$ at fasting and 1 and $2 \mathrm{~h}$ after the glucose dose, respectively, was diagnostic during both years. In both periods, a diagnosis of GDM was applied when at least one abnormal value was present in the OGTT. After the diagnosis of GDM, the patients received dietary and lifestyle counselling and began the self-monitoring of plasma glucose concentrations. According to the treatment guidelines at the time, insulin therapy was initiated if blood glucose concentrations exceeded the target levels repeatedly $(5.3 \mathrm{mmol} / \mathrm{l}$ fasting and $6.7 \mathrm{mmol} / \mathrm{l} 1.5 \mathrm{~h}$ postprandial before 2008 and $5.5 \mathrm{mmol} / \mathrm{l}$ fasting and $7.8 \mathrm{mmol} / \mathrm{l} 1 \mathrm{~h}$ postprandial thereafter). In 2006, 1126 (21.7\%) women with GDM were treated with insulin; the corresponding proportion in 2010 was 884 (13.2\%).

\section{Outcome}

Gestational age was based on the best estimate of the duration of pregnancy at delivery. During these years, systematic ultrasound examination to determine gestational age was offered to all pregnant women between $10+0$ and $13+6 \mathrm{gw}$, and detailed examination of foetal anatomy was offered between $19+0$ and $22+0 \mathrm{gw}$. The MBR data include the weight of the newborn in grams and the length in full centimetres. The ponderal index, representing the body constitution of the newborn, was calculated using weight/length $\mathrm{h}^{3}\left(\mathrm{~kg} / \mathrm{m}^{3}\right)$. Macrosomia was defined as being large for gestational age (LGA), as indicated by a birth weight that was +2 SD from a reference value (22).

Regarding neonatal outcomes, umbilical cord artery $\mathrm{pH}$, asphyxia, Apgar score and the need and indication for treatment at a neonatal ward were reported. The six most frequent neonatal diagnoses, according to the ICD-10 codes set by a pediatrician, were used to evaluate neonatal morbidity. Those diagnoses were hypoglycemia (P70.0-70.9), hyperbilirubinemia (P59.0-59.9), neonatal respiratory distress syndrome (P22.0), transient tachypnea of the newborn (P22.1), fracture of the clavicle (P13.4) and Erb's and Klumpke's palsy (P14.0; P14.1). The Current Care Guidelines recommend repeated plasma glucose measurements for all newborns of GDM mothers; for nonsymptomatic infants usually 6 measurements during the first 48 hours and for symptomatic infants more frequently. Intravenous glucose is recommended a) if a single measurement $1.4 \mathrm{mmol} / \mathrm{l}$ or less or; b) if a single measurement is 1.5 to $2.5 \mathrm{mmol} / \mathrm{l}$ and a repeated measurement after supplementary feeding is $2.5 \mathrm{mmol} / \mathrm{l}$ or less. There is no clear definition of neonatal hypoglycemia; in our experience these diagnostic codes where set when the neonate received intravenous glucose (23).

Comment [SK4]: We prefer the previous version of this sentence, but this one is ok also. 
Perinatal mortality was defined as the combined rate of stillbirth and early neonatal mortality within seventh day after birth (at home, in a neonatal ward, in a maternal ward with mother or in another

This study was approved by the regional Ethics Committee in the Northern Ostrobothnia Hospital District, Number 2008/43, date of approval 2008-6-19.

\section{Statistical analysis}

Statistical analyses were performed using IBM SPSS Statistics Versions 21 and 22. The differences between the study groups were compared by using Pearson's $\chi^{2}$ test or an independent sample t-test. P-values $<0.05$ are regarded as statistically significant. Logistic regression analyses were performed to estimate the odds ratios and 95\% confidence intervals (CIs) for the risk of outcomes consequent upon GDM in different study periods. Mean differences with 95\% CI were calculated using linear regression. We present unadjusted regression analyses and those adjusted for maternal age, parity and pre-pregnancy BMI. We also report the results after further adjusting for maternal occupational status and smoking during pregnancy. Interactions were tested by adding the product term between the two variables of interest into the regression model. 
7194

8

9195

1096

$11_{197}$

12

$13^{198}$

14

1599

16

17200

$18_{201}$

19

2002

2 bo3

22

$23^{204}$

2405

2506

2707

2808

29

30209

3210

32

$33^{211}$

3412

3513

36

37214

$38_{15}$

39

$40^{216}$

4217

42

4318

4419

$45_{22}$

46

4721

4822

49

$50^{23}$

5224

5225

5426

55

56

57

58

59

60

\section{Results}

During the risk factor-based screening in 2006, 15682 women (27.5\% of all parturients) underwent OGTT and 5179 (9.1\%) were diagnosed GDM. The corresponding rates in 2010 were 30365 (51.4\%) and $6679(11.3 \%)$, respectively (Figure SI, Table II). Unexpectedly, both the absolute number and the proportion of insulin-treated GDM mothers decreased significantly (Table III).

\section{Newborn body size and gestational age at birth}

Both the mean birth weight and the rate of LGA decreased among newborns of GDM mothers after the implementation of comprehensive screening (65 $\mathrm{g}$ from 3660 [SD 542] to $3595 \mathrm{~g}$ [SD 561] and from $5.6 \%$ to $4.1 \%$ [adjusted ORs 1.81 and 1.46 , respectively, Table SI]). In the GDM group, both the ponderal index and the absolute number of LGA cases decreased between the study years (Table II). In the control group, there was a smaller decrease in birth weight and birth weight SD score (Table II). The birth weight difference between the GDM and control groups decreased from $70 \mathrm{~g}$ to $22 \mathrm{~g}$ between the study years when adjusted for maternal age, pre-pregnancy BMI, and parity (SD scores of 0.20 and 0.11 , respectively; Table SI).

Newborns in the GDM group were born earlier than those in the control group during both study years. The difference in gestational age increased between the GDM and control groups from 0.18 to 0.25 weeks between the study years (Table II).

\section{Neonatal care}

Newborns of GDM mothers were 1.7-fold more likely to require care in a neonatal ward than controls during both study years (Table SI). The need for care at a neonatal ward decreased similarly between the study years in both the GDM and control groups (II). Although the proportion of GDM group newborns treated at a neonatal ward decreased, their absolute number did not change substantially.

\section{Neonatal complications and conditions}

Table II shows the incidence of neonatal conditions, while Table SI shows the adjusted and unadjusted odds ratios for these outcomes. The incidence of neonatal hypoglycemia clearly increased in the GDM group (18.0\% vs. $22.1 \%$ ) after the new screening policy was introduced (Tables II, III and Table SI). However, it was the most common indication for care at a neonatal ward during both study years (Tables II and III) but was less often treated at a neonatal ward during 
comprehensive screening (Table SII). Transient tachypnea was more common in infants of GDM

8

9228

mothers, but the rates of respiratory distress syndrome did not differ between the study groups.

These odds ratios were similar during both study periods, and they were attenuated after adjustment. The higher incidence of fractures of the clavicle seen in GDM group disappeared after comprehensive screening, but Erb's palsy was more common in infants of GDM mothers during both study years. Perinatal mortality rates did not differ in the GDM and control groups between the study years. (Table II).

In addition to the adjustment for maternal age, parity and pre-pregnancy BMI shown in Table SI, we further adjusted for maternal occupational status and smoking during pregnancy for most of the neonatal outcomes. This adjustment did not alter the results.

\section{Comparison of infants of GDM mothers treated with diet or insulin}

The body size and LGA rate of infants of diet-treated mothers decreased significantly from the risk factor-based to the comprehensive screening period. This change was not seen among infants of insulin-treated mothers - the ponderal index of their offspring was higher during comprehensive screening. They were also more likely to be admitted to a neonatal ward, but the difference to offspring of diet-treated mothers narrowed between the study periods. The most common indication for care at a neonatal ward with both diet- and insulin-treated mothers was neonatal hypoglycemia (Table III, SII). 


\section{Discussion}

We showed previously that the introduction of a large scale screening policy for gestational diabetes led to a significant increase in the proportion of GDM women, who mainly had a mild form of the disease (19). In the present study, we further found that in newborns, screening policy change led to decreased mean birth weight and macrosomia rates, but the prevalence of neonatal hypoglycemia increased in both diet- and insulin-treated mothers. However, this was not accompanied by an increase in care at a neonatal ward.

The need for care at a neonatal ward did not grow to the same degree as the prevalence of GDM, which may be due to the increased proportion of mild forms of disease. The amount of insulin treated GDM mothers decreased significantly, when the new uniform guidelines standardized both screening policy and cut-off levels to insulin treatment (19). However, the effect of this change to the increased incidence of neonatal hypoglycemia is unclear. Detailed new guidelines may also have encouraged a more intensive neonatal hypoglycemia screening policy in which all newborns of GDM mothers were monitored regardless of the symptoms, leading to increased hypoglycemia rates. However, the proportion of hypoglycemia as a primary indication for care at a neonatal ward did not increase, which indicates that low blood glucose concentration was mainly treated at a maternity ward with intensified oral feedings; administration of intravenous glucose generally requires treatment at a neonatal ward. The monitoring of neonatal hypoglycemia, however, places substantial demands on nursing staff and it might be worth considering whether systematic monitoring to this extent is necessary. Therefore, we agree with the conclusion of the Atlantic Diabetes in Pregnancy study arguing that the new comprehensive screening requires a great deal of manpower and resources, although it provides an opportunity to reduce the morbidity of the mother and infant (24).

Infants of GDM mothers are known to require care at a neonatal ward more often than infants of non-GDM mothers $(5,24)$, which was also seen in the present study. To some extent, the threshold for follow-up at a neonatal ward may be lower in GDM cases than in controls; it may also vary between hospitals. In the present study, in-ward treatment decreased to the same degree in both the GDM and control groups, which may reflect a common trend of supporting rooming-in instead of separating the mother from her newborn. In addition, optimal GDM treatment is known to decrease the risk of severe neonatal morbidity (15). Although the proportion of infants treated in a neonatal ward decreased, their absolute number remained nearly the same because of an increased number of GDM pregnancies. 
During comprehensive screening, infants born to GDM mothers had lower birth weight and birth weight SD and were less likely to be macrosomic compared to risk factor-based screening. The decrease was accompanied by a lower rate of clavicle fracture. However, the decrease of macrosomia was limited to the diet-treated group, also after adjustment for maternal age, parity and pre-pregnancy BMI..There are two possible explanations for this decrease. First, comprehensive screening possibly identifies milder cases, and therefore, macrosomia is less probable. Another explanation is that the reduction is a result of uniform counselling and follow-up based on the new Current Guidelines. Indeed, treatment of mild GDM has been shown to reduce the risk of macrosomia $(15,17)$.

The strength of our study is that it included a large, unselected study population based on comprehensive national register data. In Finland, virtually all pregnant women receive maternal health care free of charge and give birth in a public hospital. Therefore, systematic and unselected data acquisition is possible. The coverage of the Finnish MBR is practically complete, and most variables are of high quality. Because of the study design, however, we did not have data on woman's previous pregnancies; therefore, we were unable to estimate the exact proportion of very low risk women for whom the new guidelines do not recommend OGTT or to evaluate the significance of specific GDM risk factors during different study periods.

In conclusion, comprehensive GDM screening detects more cases of GDM, but these are less severe. This is also reflected in the neonatal outcomes: During comprehensive screening, infants of GDM mothers were smaller, less often macrosomic and required care in a neonatal ward less often. Although the proportion of infants treated at a neonatal ward did not increase in the same relation with the total GDM cases, the increased prevalence of GDM and neonatal hypoglycemia placed substantial demands on the nursing staff and the delivery hospitals. 
7309 Acknowledgements: None.

8310

$1 ß 11$ Funding: The study was supported by grants from the Academy of Finland, Emil Aaltonen

131 12 14 141 15 $16^{31}$ 17316

18317 $2 ळ 18$

21

22

23

24

25

26

27

28

29

30

31

32

33

34

35

36

37

38

39

40

41

42

43

44

45

46

47

48

49

50

51

52

53

54

55

56

57

58

59

60

Foundation, the Foundation of Cardiovascular Research, the Foundation of Paediatric Research, the

National Graduate School of Clinical Investigation, the Novo Nordisk Foundation, Pohjois-Suomen

Terveydenhuollon tukisäätiö, Signe and Ane Gyllenberg Foundation, and the Sigrid Juselius

Foundation, Yrjö Jahnsson Foundation. 
References

1. Soler NG, Soler SM, Malins JM. Neonatal morbidity among infants of diabetic mothers. Diabetes Care. 1978; $1: 340-50$.

2. Taricco E, Radaelli T, Rossi G, Nobile de Santis MS, Bulfamante GP, Avagliano L, et al. Effects of gestational diabetes on fetal oxygen and glucose levels in vivo. BJOG: An International Journal of Obstetrics \& Gynaecology. 2009; 116: 1729-35.

3. HAPO Study Cooperative Research G, Metzger BE, Lowe LP, Dyer AR, Trimble ER, Chaovarindr U, et al. Hyperglycemia and adverse pregnancy outcomes. N Engl J Med. 2008; 358: 1991-2002.

4. Reece EA, Leguizamon G, Wiznitzer A. Gestational diabetes: The need for a common ground. Lancet. 2009; 373: 1789-97.

5. Ju H, Rumbold AR, Willson KJ, Crowther CA. Borderline gestational diabetes mellitus and pregnancy outcomes. BMC Pregnancy \& Childbirth. 2008; 8: 31.

6. Catalano PM, McIntyre HD, Cruickshank JK, McCance DR, Dyer AR, Metzger BE, et al. The hyperglycemia and adverse pregnancy outcome study: Associations of GDM and obesity with pregnancy outcomes. Diabetes Care. 2012; 35: 780-6.

7. Gillman MW, Rifas-Shiman S, Berkey CS, Field AE, Colditz GA. Maternal gestational diabetes, birth weight, and adolescent obesity. Pediatrics. 2003; 111: e221-6.

8. Boney CM, Verma A, Tucker R, Vohr BR. Metabolic syndrome in childhood: Association with birth weight, maternal obesity, and gestational diabetes mellitus. Pediatrics. 2005; 115: e290-6.

9. Pirkola J, Pouta A, Bloigu A, Miettola S, Hartikainen AL, Järvelin MR, et al. Prepregnancy overweight and gestational diabetes as determinants of subsequent diabetes and hypertension after 20 -year follow-up. J Clin Endocrinol Metab. 2010; 95: 772-8. 
7341 10. Vaarasmaki M, Pouta A, Elliot P, Tapanainen P, Sovio U, Ruokonen A, et al. Adolescent manifestations 8

9342 of metabolic syndrome among children born to women with gestational diabetes in a general-population 10 $11^{34}$ 12 11. Borgono CA, Hamilton JK, Ye C, Hanley AJ, Connelly PW, Sermer M, et al. Determinants of insulin resistance in infants at age 1 year: Impact of gestational diabetes mellitus. Diabetes Care. 2012; 35: $1795-7$.

12. Malcolm J. Through the looking glass: Gestational diabetes as a predictor of maternal and offspring longterm health. Diabetes Metab Res. 2012; 28: 307-11.

13. Nilsson C, Carlsson A, Landin-Olsson M. Increased risk for overweight among swedish children born to mothers with gestational diabetes mellitus. Pediatr Diabetes. 2014; 15: 57-66.

14. Sacks DA, Hadden DR, Maresh M, Deerochanawong C, Dyer AR, Metzger BE, et al. Frequency of gestational diabetes mellitus at collaborating centers based on IADPSG consensus panel-recommended criteria: The hyperglycemia and adverse pregnancy outcome (HAPO) study. Diabetes Care. 2012; 35: 526-8. 15. Crowther CA, Hiller JE, Moss JR, McPhee AJ, Jeffries WS, Robinson JS, et al. Effect of treatment of gestational diabetes mellitus on pregnancy outcomes. N Engl J Med. 2005; 352: 2477-86.

16. Clausen TD, Mathiesen ER, Hansen T, Pedersen O, Jensen DM, Lauenborg J, et al. Overweight and the metabolic syndrome in adult offspring of women with diet-treated gestational diabetes mellitus or type 1 diabetes. J Clin Endocrinol Metab. 2009; 94: 2464-70.

17. Landon MB, Spong CY, Thom E, Carpenter MW, Ramin SM, Casey B, et al. A multicenter, randomized trial of treatment for mild gestational diabetes. N Engl J Med. 2009; 361: 1339-48.

18. Moore TR. Fetal exposure to gestational diabetes contributes to subsequent adult metabolic syndrome. Am J Obstet Gynecol. 2010; 202: 643-9. 
20. Gissler M, Teperi J, Hemminki E, Merilainen J. Data quality after restructuring a national medical registry. Scand J Soc Med. 1995; 23: 75-80.

21. Gissler M, Shelley J. Quality of data on subsequent events in a routine medical birth register. Med Inform Internet Med. 2002; 27: 33-8.

22. Pihkala J, Hakala T, Voutilainen P, Raivio K. Characteristic of recent fetal growth curves in finland. Duodecim. 1989; 105: 1540-6.

23. Finnish Medical Society Duodecim. Cuurent care guidelines for gestational diabetes. helsinki, finland: The finnish medical society duodecim. . 2008.

24. O'Sullivan EP, Avalos G, O'Reilly M, Dennedy MC, Gaffney G, Dunne F, et al. Atlantic diabetes in pregnancy (DIP): The prevalence and outcomes of gestational diabetes mellitus using new diagnostic criteria. Diabetologia. 2011; 54: 1670-5. 


\section{Legends of figures and tables}

Table I. The GDM screening indications and proportion of GDM diagnoses in the study years.

Table II. Clinical characteristics and outcome in GDM and control mothers and their offspring during risk factor-based (year 2006) and comprehensive (2010) GDM screening.

Table III. Clinical characteristics and outcome of mothers and their offspring divided according to diet and insulin treatment during risk factor-based (year 2006) and comprehensive (2010) screening.

Supplementary Table I (Table SI). Odds ratios (for dichotomous outcomes) and mean differences (for continuous outcomes) comparing mothers with GDM and their offspring to control mothers and their offspring during risk factor-based (year 2006) and comprehensive (2010) screening. P-values for interaction indicate whether the association of GDM with the outcome is different during comprehensive as compared to risk factor-based screening.

Supplementary Table II (Table SII). Diagnoses of infants admitted to the neonatal ward.

Supplementary Figure I (Figure SI). Flow chart of the study. 
Table I: The GDM screening indications and proportion of GDM diagnoses in the study years

\begin{tabular}{|c|c|c|c|}
\hline \multicolumn{2}{|c|}{ OGTT screening population* } & \multirow{2}{*}{$\begin{array}{l}\text { OGTT performed, } \\
\mathrm{n}(\% \text { of all included } \\
\text { mothers })\end{array}$} & \multirow{2}{*}{$\begin{array}{l}\text { Gestational diabetes } \\
\text { diagnosed, } \mathrm{n}(\% \text { of all } \\
\text { included mothers })\end{array}$} \\
\hline $\begin{array}{l}\text { Risk factor- } \\
\text { based screening } \\
(2006)\end{array}$ & \begin{tabular}{||l} 
Screening based on risk factors \\
- Prior GDM \\
- Overweight $\left(\mathrm{BMI}^{\dagger}>25 \mathrm{~kg} / \mathrm{m}^{2}\right)$ \\
- Alucosuria \\
- Previous macrosomic newborn $(>4500 \mathrm{~g})$ \\
- Suspected macrosomia in the current \\
$\quad$ pregnancy
\end{tabular} & & \\
\hline $\begin{array}{l}\text { Comprehensive } \\
\text { screening (2010) }\end{array}$ & \begin{tabular}{|l} 
All women, excluding those with very low GDM \\
risk: \\
Primiparous: \\
- Age $<25$ years \\
- BMI $\dagger<25 \mathrm{~kg} / \mathrm{m}^{2}$ \\
- No family history of diabetes \\
Parous: \\
- Age $<40$ years \\
- BMI ${ }^{\dagger}<25 \mathrm{~kg} / \mathrm{m} 2$ \\
- No prior GDM \\
No previous macrosomic newborn
\end{tabular} & $30365\left(51.4 \% \%^{\ddagger}\right)$ & $6679(11.3 \% \neq)$ \\
\hline
\end{tabular}

* OGTT $=$ oral glucose tolerance test: cut-off levels of glucose concentrations in venous plasma $\geq 5.3,10.0$ and $8.6 \mathrm{mmol} / 1$ at fasting and 1 and $2 \mathrm{~h}$ after the $75 \mathrm{~g}$ glucose load tBody mass index $\left(\mathrm{kg} / \mathrm{m}^{2}\right)$

₹ The proportion of all included mothers that year, $\mathrm{N}=56925$ in 2006 and $\mathrm{N}=59065$ in 2010 . 
Table II. Clinical characteristics and outcome in GDM and control mothers and their offspring during risk factor-based (year 2006) and comprehensive (2010) GDM screening.

\begin{tabular}{|c|c|c|c|c|c|c|}
\hline Characteristic & GDM 2006 & GDM 2010 & P-value & Control 2006 & Control 2010 & P-value \\
\hline $\mathrm{N}(\%)$ & $5179(9.1)$ & $6679(11.3)$ & & $51746(90.9)$ & $52386(88.7)$ & \\
\hline Maternal age, years (SD) & $31.09(5.65)$ & $31.02(5.45)$ & 0.526 & $29.30(5.37)$ & $29.39(5.27)$ & 0.007 \\
\hline Primiparous, n (\%) & $1787(34.5)$ & $2634(39.4)$ & $<0.001$ & $22226(43.1)$ & $22290(42.6)$ & 0.084 \\
\hline BMI before pregnancy, $\mathrm{kg} / \mathrm{m}^{2 *}(\mathrm{SD})$ & $28.6(5.82)$ & $28.2(6.11)$ & $<0.001$ & $23.7(4.26)$ & $23.8(4.36)$ & $<0.001$ \\
\hline \multicolumn{7}{|l|}{ Neonatal characteristics } \\
\hline Gestational age, weeks (SD) & $39.65(1.61)$ & $39.62(1.66)$ & 1.000 & $39.83(1.79)$ & $39.87(1.75)$ & 0.001 \\
\hline Preterm births, < 37 wk, n (\%) & $246(4.7)$ & $348(5.2)$ & 0.254 & $2286(4.4)$ & $2174(4.1)$ & 0.033 \\
\hline Birth weight, grams (SD) & $3660(542)$ & $3595(561)$ & $<0.001$ & $3515(545)$ & $3505(539)$ & 0.003 \\
\hline Length at birth, cm (SD) & $50.5(2.25)$ & $50.3(2.40)$ & $<0.001$ & $50.1(2.47)$ & $50.1(3.18)$ & 0.672 \\
\hline Ponderal index, $\mathrm{kg} / \mathrm{m}^{3}$ (SD) & $28.3(2.70)$ & $28.1(3.22)$ & $<0.001$ & $27.9(3.41)$ & $27.8(4.02)$ & 0.015 \\
\hline $\mathrm{LGA} \dagger, \mathrm{n}(\%)$ & $289(5.6)$ & $276(4.1)$ & $<0.001$ & $1011(2.0)$ & $966(1.8)$ & 0.153 \\
\hline \multicolumn{7}{|l|}{ Neonatal outcomes } \\
\hline 5 min Apgar score < 7, n (\%) & $109(2.1)$ & $136(2.0)$ & 0.795 & $974(1.9)$ & $1049(2.0)$ & 0.160 \\
\hline Cord arterial $\mathrm{pH}<7.15, \mathrm{n}(\%)$ & $333(6.4)$ & $505(7.6)$ & 0.017 & $3305(6.4)$ & $3755(7.2)$ & $<0.001$ \\
\hline Asphyxia, n (\%) & $206(4.0)$ & $371(5.6)$ & $<0.001$ & $2167(4.2)$ & $2712(5.2)$ & $<0.001$ \\
\hline \multicolumn{7}{|l|}{ Neonatal care } \\
\hline Location of the newborn at 7 days of age, $n(\%)$ & & & $0 \cap 01$ & & & $<0.001$ \\
\hline Home & $4871(94.1)$ & $6144(92.0)$ & & $48694(94.1)$ & $48723(93.0)$ & \\
\hline Maternity ward & $70(1.4)$ & & & & $2024(3.9)$ & \\
\hline Other ward & $180(3.5)$ & & & $1511(2.9)$ & & \\
\hline Admitted to neonatal ward, $\mathrm{n}(\%)$ & $834(16.1)$ & $861(12.9)$ & $<0.001$ & $5075(9.8)$ & $4119(7.9)$ & $<0.001$ \\
\hline Transferred to other hospital, n (\%) & $38(0.7)$ & $112(1.7)$ & $<0.001$ & $311(0.6)$ & $649(1.2)$ & $<0.001$ \\
\hline Perinatal mortality, $\mathrm{n}(\%)$ & $16(0.3)$ & $22(0.3)$ & 0.919 & $237(0.5)$ & $187(0.4)$ & 0.012 \\
\hline \multicolumn{7}{|l|}{ Neonatal diagnoses } \\
\hline Hypoglycemia, n (\%) & $932(18.0)$ & $1478(22.1)$ & $<0.001$ & $1371(2.6)$ & $1407(2.7)$ & 0.716 \\
\hline Neonatal RDS & $18(0.3)$ & $15(0.2)$ & 0.207 & $202(0.4)$ & $139(0.3)$ & $<0.001$ \\
\hline Transient tachypnea, n (\%) & $85(1.6)$ & $120(1.8)$ & 0.520 & $656(1.3)$ & $670(1.3)$ & 0.872 \\
\hline Hyperbilirubinemia, n (\%) & $303(5.9)$ & $324(4.9)$ & 0.016 & $2160(4.2)$ & $1776(3.4)$ & $<0.001$ \\
\hline Fracture of the clavicle, $\mathrm{n}(\%)$ & $87(1.7)$ & $53(0.8)$ & $<0.001$ & $533(1.0)$ & $378(0.7)$ & $<0.001$ \\
\hline Erb's or Klumpke's palsy, n (\%) & $26(0.5)$ & $22(0.3)$ & 0.142 & $120(0.2)$ & $72(0.1)$ & 0.0004 \\
\hline
\end{tabular}

The numbers are $\mathrm{n}(\%)$ or mean $(\mathrm{SD})$

*Body mass index $\left(\mathrm{kg} / \mathrm{m}^{2}\right)$; $\uparrow$ Large for gestational age $(>+2 \mathrm{SD}) ;+$ Respiratory distress syndrome. 
Table III. Clinical characteristics and outcome of mothers and their offspring divided according to diet and insulin treatment during risk factor-based (year 2006) and comprehensive (2010) screening.

\begin{tabular}{|c|c|c|c|c|c|c|}
\hline Characteristic & Diet 2006 & Diet 2010 & P-value & Insulin 2006 & Insulin 2010 & P-value \\
\hline$\overline{N(\%)}$ & $4053(78.3)$ & $5795(86.8)$ & $<0.001$ & $1126(21.7)$ & $884(13.2)$ & $<0.001$ \\
\hline Maternal age, years (SD) & $30.9(5.7)$ & $30.0(5.4)$ & 0.504 & $31.7(5.6)$ & $32.1(5.4)$ & 0.071 \\
\hline Primiparous, $\mathrm{n}(\%)$ & $1403(34.6)$ & $2325(40.1)$ & $<0.001$ & $384(34.0)$ & $310(35.0)$ & 0.665 \\
\hline $\mathrm{BMI}^{*}$ before pregnancy, $\mathrm{kg} / \mathrm{m}^{2}(\mathrm{SD})$ & $28.6(5.7)$ & $27.9(5.9)$ & $<0.001$ & $28.8(6.3)$ & $30.2(6.9)$ & $<0.001$ \\
\hline \multicolumn{7}{|l|}{ Neonatal characteristics } \\
\hline Gestational age, weeks (SD) & $39.77(1.56)$ & $39.67(1.70)$ & 0.020 & $39.23(1.71)$ & $39.27(1.38)$ & 1.000 \\
\hline Preterm births, $<37$ wk, n (\%) & $172(4.2)$ & $304(5.2)$ & 0.022 & $74(6.6)$ & $44(5.0)$ & 0.131 \\
\hline Birth weight, grams (SD) & $3674(540)$ & $3587(564)$ & $<0.001$ & $3613(546)$ & $3644(540)$ & 0.202 \\
\hline Length at birth, cm (SD) & $50.52(2.24)$ & $50.31(2.42)$ & $<0.001$ & $50.36(2.26)$ & $50.25(2.25)$ & 0.258 \\
\hline Ponderal index, kg/m3 (SD) & $28.38(2.68)$ & $28.04(3.21)$ & $<0.001$ & $28.12(2.75)$ & $28.68(3.25)$ & $<0.001$ \\
\hline LGA $\uparrow, \mathrm{n}(\%)$ & $216(5.3)$ & $213(3.7)$ & $<0.001$ & $73(6.5)$ & $63(7.1)$ & 0.564 \\
\hline \multicolumn{7}{|l|}{ Neonatal outcomes } \\
\hline 5 min Apgar score < 7, n (\%) & $80(2.8)$ & $118(2.0)$ & 0.824 & $31(2.7)$ & $19(2.1)$ & 0.385 \\
\hline Cord arterial $\mathrm{pH}<7.15, \mathrm{n}(\%)$ & $253(6.2)$ & $448(7.7)$ & 0.005 & $80(7.1)$ & $57(6.4)$ & 0.562 \\
\hline Asphyxia, n (\%) & $161(4.0)$ & $321(5.5)$ & $<0.001$ & $45(4.0)$ & $50(5.7)$ & 0.082 \\
\hline \multicolumn{7}{|l|}{ Neonatal care } \\
\hline Location of the newborn at 7-days of age, & & & $<0.001$ & & & $<0.001$ \\
\hline Home & $3834(94.6)$ & $5333(92.0)$ & & $1037(92.1)$ & $811(91.7)$ & \\
\hline Maternity ward & $55(1.4)$ & $234(4.0)$ & & $15(1.3)$ & $39(4.4)$ & \\
\hline Other ward & $123(3.0)$ & $191(3.3)$ & & $57(5.1)$ & $30(3.4)$ & \\
\hline Other hospital & $21(0.5)$ & $20(0.3)$ & & $4(0.4)$ & $4(0.5)$ & \\
\hline Deceased & $12(0.3)$ & $15(0.3)$ & & $1(0.1)$ & $0(0.0)$ & \\
\hline Admitted to neonatal ward, $\mathrm{n}(\%)$ & $531(13.1)$ & $710(12.3)$ & 0.211 & $303(26.9)$ & $151(17.1)$ & $<0.001$ \\
\hline Child transferred to other hospital, n (\%) & $31(0.8)$ & $97(1.7)$ & $<0.001$ & $7(0.6)$ & $15(1.7)$ & 0.021 \\
\hline Perinatal mortality, $\mathrm{n}(\%)$ & $15(0.4)$ & $22(0.4)$ & 0.875 & $1(0.09)$ & $0(0.0)$ & 0.375 \\
\hline \multicolumn{7}{|l|}{ Neonatal diagnoses } \\
\hline Hypoglycemia, n (\%) & $619(15.3)$ & $1184(20.4)$ & $<0.001$ & $313(27.8)$ & $294(33.3)$ & 0.008 \\
\hline Neonatal RDS $\neq, \mathrm{n}(\%)$ & $10(0.2)$ & $12(0.2)$ & 0.682 & $8(0.7)$ & $3(0.3)$ & 0.263 \\
\hline Transient tachypnea, n (\%) & $65(1.6)$ & $107(1.8)$ & 0.366 & $20(1.8)$ & $13(1.5)$ & 0.593 \\
\hline Hyperbilirubinemia, n (\%) & $199(4.9)$ & $256(4.4)$ & 0.252 & $104(9.2)$ & $68(7.7)$ & 0.219 \\
\hline Fracture of the clavicle, n $(\%)$ & $74(1.8)$ & $51(0.9)$ & $<0.001$ & $14(1.2)$ & $3(0.3)$ & 0.028 \\
\hline Erb's or Klumpke's palsy, n (\%) & $16(0.4)$ & $19(0.3)$ & 0.653 & $10(0.9)$ & $3(0.3)$ & 0.127 \\
\hline
\end{tabular}

The numbers are $\mathrm{n}(\%)$ or mean $(\mathrm{SD})$.

$*$ Body mass index $\left(\mathrm{kg} / \mathrm{m}^{2}\right) ; \uparrow$ Large for gestational age $(>+2 \mathrm{SD}) ;+$ Respiratory distress syndrome 
Supplementary Table IV. Odds ratios (for dichotomous outcomes) and mean differences (for continuous outcomes) comparing mothers with GDM and their offspring to control mothers and their offspring during risk factor-based (year 2006) and comprehensive (2010) screening. P-values for interaction indicate whether the association of GDM with the outcome is different during comprehensive as compared to risk factor-based screening.

\begin{tabular}{|c|c|c|c|c|c|c|c|c|c|}
\hline & \multicolumn{2}{|c|}{2006 Unadjusted } & \multicolumn{2}{|c|}{2006 Adjusted $\S$} & \multicolumn{2}{|c|}{2010 Unadjusted } & \multicolumn{2}{|c|}{2010 Adjusted $\S$} & \multirow{2}{*}{$\begin{array}{c}\text { Un-/ } \\
\text { Adjusted } \S \\
\text { p-value for } \\
\text { interaction }\end{array}$} \\
\hline & $\begin{array}{c}\text { Mean } \\
\text { difference/ } \\
\text { OR }^{*}\end{array}$ & $95 \%$ CI & $\begin{array}{c}\text { Mean } \\
\text { difference/ } \\
\text { OR } \\
\end{array}$ & $95 \% \mathrm{CI}$ & $\begin{array}{c}\text { Mean } \\
\text { difference/ } \\
\text { OR } \\
\end{array}$ & $95 \% \mathrm{CI}$ & $\begin{array}{c}\text { Mean } \\
\text { difference/ } \\
\text { OR } \\
\end{array}$ & $95 \%$ CI & \\
\hline Gestational age, wk & -0.18 & $-0.23,-0.13$ & -0.19 & $-0.24,-0.14$ & -0.26 & $-0.30,-0.21$ & -0.29 & $-0.34-0.24$ & $0.026 / 0.026$ \\
\hline Preterm births & 1.08 & $0.94-1.23$ & 1.02 & $0.88-1.18$ & 1.27 & $1.13-1.43$ & 1.26 & 1.11-1.42 & $0.07 / 0.06$ \\
\hline Birth weight (g) & 145 & $129-160$ & 70 & 54-87 & 89 & $76-103$ & 22 & 8-37 & $<0.001 /<0.001$ \\
\hline Birth weight SD score & 0.37 & $0.34-0.40$ & 0.20 & $0.17-0.22$ & 0.26 & $0.25-0.29$ & 0.11 & $0.09-0.14$ & $<0.001 /<0.001$ \\
\hline Ponderal index, $\mathrm{kg} / \mathrm{m} 3$ & 0.47 & $0.37-0.56$ & 0.20 & $0.09-0.30$ & 0.33 & $0.23-0.43$ & 0.14 & $0.04-0.25$ & $0.054 / 0.054$ \\
\hline LGA $\dagger$ & 2.95 & $2.58-3.37$ & 1.81 & $1.56-2.10$ & 2.29 & $2.00-2.63$ & 1.46 & $1.26-1.69$ & $0.010 / 0.051$ \\
\hline Care in neonatal ward & 1.77 & $1.63-1.91$ & 1.50 & $1.38-1.64$ & 1.73 & $1.60-1.88$ & 1.48 & $1.36-1.61$ & $0.756 / 0.837$ \\
\hline Hypoglycemia & 8.06 & 7.38-8.81 & 6.20 & $5.61-6.86$ & 10.3 & 9.52-11.14 & 8.40 & 7.71-9.15 & $<0.001 /<0.0001$ \\
\hline
\end{tabular}

*OR, odds ratio; †Large for gestational age (+ 2 SD); † Respiratory distress syndrome; § Adjusted for maternal age, parity and pre-pregnancy BMI 
| Supplementary Table II. Diagnoses of infants admitted to the neonatal ward.

\begin{tabular}{|c|c|c|c|c|c|c|}
\hline \multirow[b]{2}{*}{ Characteristic } & \multicolumn{2}{|c|}{ GDM } & \multicolumn{3}{|c|}{ Controls } & \multirow[b]{2}{*}{ P-value } \\
\hline & 2006 & 2010 & P-value & 2006 & 2010 & \\
\hline $\mathrm{N}(\% *)$ & $834\left(16.1^{*}\right)$ & $861(12.9 *)$ & & $5075\left(9.8^{*}\right)$ & $4119\left(7.9^{*}\right)$ & \\
\hline $\mathrm{LGA} \dagger, \mathrm{n}(\%)$ & $72(8.6)$ & $53(6.2)$ & 0.051 & $147(2.9)$ & $134(3.3)$ & 0.323 \\
\hline \multicolumn{7}{|l|}{ Diagnoses-among them } \\
\hline Hypoglycemia, n (\%) & $410(49.2)$ & $385(44.7)$ & 0.067 & $928(18.3)$ & $722(17.5)$ & 0.347 \\
\hline Asphyxia, n (\%) & $71(8.5)$ & $50(5.8)$ & 0.017 & $504(9.9)$ & $444(10.8)$ & 0.183 \\
\hline RDS $+\mathrm{n}(\%)$ & $16(1.9)$ & $15(1.7)$ & 0.787 & $197(3.9)$ & $133(3.2)$ & 0.094 \\
\hline Transient tachypnea, n (\%) & $69(8.3)$ & $84(9.8)$ & 0.287 & $528(10.4)$ & $497(12.1)$ & 0.012 \\
\hline Hyperbilirubinemia, n (\%) & $120(14.4)$ & $106(12.3)$ & 0.208 & $708(14.0)$ & $534(13.0)$ & 0.169 \\
\hline Fracture of the clavicle, $\mathrm{n}(\%)$ & $16(1.9)$ & $7(0.8)$ & 0.049 & $63(1.2)$ & $37(0.9)$ & 0.115 \\
\hline Erb's or Klumpke's palsy, n (\%) & $5(0.6)$ & $4(0.5)$ & 0.702 & $26(0.5)$ & $14(0.3)$ & 0.212 \\
\hline Asphyxia, $n(\%)$ & $71(8.5)$ & $50(5.8)$ & 0.017 & $504(9.9)$ & $-444(10.8)$ & 0.183 \\
\hline
\end{tabular}

$* \%$ of all infants in that group and that year; $\dagger$ Large for gestational age ( $>+2 \mathrm{SD}) ; \ddagger$ Respiratory distress syndrome. 

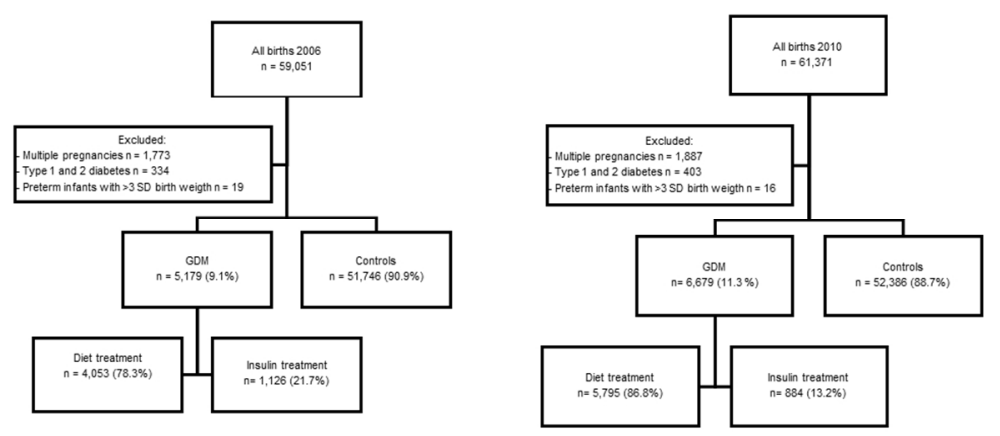

Flow chart of the study. Figure SI

$338 \times 190 \mathrm{~mm}(96 \times 96$ DPI) 